\title{
UK scrutiny of public labs under fire from Parliament
}

London. A select committee of the UK House of Lords is the latest body to raise strong objections to both the procedures and conclusions of a civil service inquiry into the 'efficiency' of a number of publicly funded research laboratories.

The committee's criticism could prove the final nail in the coffin of the government's apparent enthusiasm for the privatization of a significant number of these laboratories (including their possible "purchase' by universities). Reforms, though still anticipated, are likely to be evolutionary rather than revolutionary.

The so-called 'efficiency scrutiny' was carried out earlier this year by a group of civil servants. The Cabinet Office's efficiency unit asked them to look at 53 government laboratories, and in particular to explore which of them might be privatized.

Although its preliminary report, published in April, found little scope for widespread privatization, the scrutiny team did suggest two ways of grouping the laboratories - either by geographic region or by scientific discipline - as well as various other changes (see Nature 368, 681; 1994)

But in a report published last week based on evidence presented by scientific bodies and other organizations, the House of Lords Select Committee on Science and Technology criticizes virtually all of the review team's proposals as unnecessary and potentially damaging to the UK science base.

The only conclusion it supports is that there should be a greater flexibility in Treasury rules, allowing research establishments to operate more commercially. But it rejects both of the alternative models proposed by the review team for grouping the laborato-

\section{Research body revives 'Faraday' concept}

London. The UK Engineering and Physical Sciences Research Council (EPSRC) is reviving proposals to create a network of 'Faraday centres' - named after the nineteenth century British physicist, and modelled loosely on Germany's Fraunhofer Institutes - to act as a bridge between industry and academic institutions.

The proposals were first made in 1991, by a commission headed by the Prince of Wales, and revived by the Conservative government during the 1992 general election campaign. But Michael Heseltine, the president of the Board of Trade, later dropped the idea on the grounds that the government had little interest in new institutional initiatives.

Last week, Alan Rudge, the chairman of EPSRC and board member with re- ries, criticizes its "narrow terms of reference", and describes the choices of establishments scrutinized as "haphazard".

"We believe that the whole report was misconceived," says the Earl of Selborne, the chairman of the select committee, and himself a former chairman of the Natural Environment Research Council. "It was reasonable for the government's efficiency unit to scrutinize an area of major public expense; but the way this exercise was carried out was totally inappropriate."

Selborne said that the committee had been particularly concerned that the team's original terms of reference placed a stronger emphasis on privatization than on any other model of reorganization, adding that "the exercise appears to have been Treasury-led rather than science-led".

The report itself, echoing sentiments from bodies ranging from the Royal Society to the Institute of Professionals, Managers and Specialists (the labour union representing most of the staff in the bodies being scrutinized), continues: "We do not believe that sufficient attention has been paid to the question of the effectiveness of public sector science in the pursuit of wealth creation and quality of life, without which any study of the efficiency of the management of that

Speaking last month in front of a House of Commons committee (which later published an equally critical report) David Hunt, the new cabinet minister for science, said that he had an open mind about his eventual reaction to the scrutiny team's recommendations. But there now seems little prospect that the major changes it proposed in April will be adopted full-scale. David Dickson

sponsibility for research and procurement at BT, told a meeting of industrialists that it was time to take another look at the idea. "We are studying it closely to see whether it could be encouraged jointly with the Department of Trade and Industry."

The attraction of the 'Faraday principle', he said, is that it would provide a way of building up 'intermediate institutions' with links to universities and other academic bodies on the one hand and with industry on the other.

At the same time, Rudge warned universities that placing excessive emphasis on intellectual property rights of discoveries risked impeding efforts to build closer ties with industry. This could "slow the whole process. science has little value."

\section{Research council to require plan of proposed projects}

London. Britain's largest research funding agency, the Engineering and Physical Sciences Research Council (EPSRC), is to require all grant applicants to provide a diagram on a single sheet of paper demonstrating how they intend the goals of their research project to be achieved.

The project will subsequently be evaluated partly on the basis of its success in achieving these goals. The move represents part of a new strategy being developed by EPSRC officials to increase the effort that goes into assessing the output of research projects - not merely their scientific potential.

Some scientists, while welcoming the council's attempts to increase the costeffectiveness of its grant-giving practices, are wary of possible dangers in placing excessive emphasis on the achievement of pre-selected goals. "I would be worried if researchers started to play safe with their applications, only stating goals that they were confident of achieving" says physicist John Mulvey of the group Save British Science.

But Alan Rudge, the chairman of EPSRC, told a meeting of industrialists in London last week that in the past, while a great deal of effort had been placed on selecting grants for funding, relatively little had been spent on auditing what had been achieved. "I think that we have had the wrong balance," he said.

According to EPSRC officials, all grant applicants will therefore in future be asked to identify the criteria by which they would like the outcome of their research to be judged. Included in this process will be a one-page diagram of "the logic of their proposal". If a scientist feels unable to produce such a chart, "then peer reviewers will have to say whether they agree with that assessment".

Rudge claims that, although the evaluation of basic research needs to be approached with a "slightly different attitude" to applied research directed at specific goals, "it is an illusion that you cannot have any peer review of the way in which you intend to go about a programme." Even basic researchers, said Rudge, needed a plan of the route they intended to follow. "When you audit a project, you audit it against a plan," he says. "Even basic research has an objective."

Another proposal being studied to increase the effective evaluation of EPSRCsponsored research projects, said Rudge, is the organization of 'theme days' during which EPSRC-sponsored research groups would demonstrate their work to interested industrialists and other potential customers for their results. 